\title{
Reduced Kinetic Scheme of Methane/Oxygen Combustion for Liquid Rocket Engine Applications
}

\author{
Guido Saccone, Pasquale Natale, Francesco Battista \\ CIRA (Italian Aerospace Research Centre) \\ Via Maiorise snc, Capua (CE), Italy \\ g.saccone@cira.it; p.natale@cira.it; f.battista@cira.it
}

\section{Extended Abstract}

HYPROB-NEW project, carried out by CIRA (Italian Aerospace Research Centre) and funded by the Italian Ministry of University and Research, aimed to improve the national system and competences on Liquid Rocket Engines (LRE) for future space applications, with specific regard to $\mathrm{LO}_{\mathrm{x}} / \mathrm{LCH}_{4}$ (liquid oxygen/liquid methane) technology.

In that framework, it is of fundamental importance to set up a suitable physical-chemical model, able to reproduce the challenging phenomena occurring inside LRE thrust chambers (i.e., turbulence, chemical reactions, high temperature and pressure, multiphase and multicomponent flow dynamics). At the same time, the model should be suitable for the accuracy and computational costs required. For that purpose, the chemistry-turbulence interaction models play a key role in the modelling definition.

Previous investigations [1] showed that a very easy combustion model—e.g., Eddy Dissipation Model (EDM) [2]—is almost completely unsatisfactory, since it is unable to correctly predict the overall experimental flame temperature and pressure of the thrust chamber. Instead, a more detailed chemical kinetic approach, i.e., Laminar Finite Rate (LFR), is more suitable, in order to obtain a closer correspondence with experimental values for pressure and temperature in the combustion chamber. Moreover, LFR is also suitable for a more detailed comparison between computational and experimental concentrations of chemical species.

The work here reported presents the chemical kinetic reduction methodology of a detailed mechanism, i.e., RAMEC [3], suitable for specific applications where high-pressure methane/oxygen combustion is involved. For that purpose, the open-source, 0D kinetic code CANTERA [5], under Python interface, was adopted.

The first step of the reduction was achieved by means of reaction path analysis tracking the carbon atom. This method allowed the recognition of both the high-pressure oxidation path and the pyrolytic one. In fact, due to the fuel rich mixture, heavier hydrocarbons are involved, such as $\mathrm{C}_{2} \mathrm{H}_{3}$. Thus, all the chemical species and the corresponding reactions not included in these two reaction paths were eliminated.

In this way, a simplified skeletal kinetic scheme, containing 113 elementary steps, was obtained.

The second step consisted in sensitivity analysis [4]. It was performed using reaction rates of all reactions (selected from the previous reduction step) as input. Flame temperature was chosen instead as the reference variable. This step has allowed the cut of the not rate-limiting reactions and a further simplification to less than 50 elementary steps.

The main objective was to set up a skeletal kinetic scheme, tailored at the same temperature, pressure and chemical composition range of HYPROB-NEW final technological demonstrator and specifically conceived as a chemical model to be embedded into Computational Fluid Dynamic (CFD) 3D Reynolds Averaged Navier Stokes (RANS) LFR simulations.

Moreover, ignition delay times and adiabatic flame temperatures were calculated in several operative conditions by means of Cantera simulations, using both the proposed skeletal kinetic scheme and the main simplified mechanisms available in literature. Finally, a comparison among these data was performed for a preliminary verification.

\section{References}

[1] P. Natale, G. Saccone, A. French, F. Battista, "Chemical and CFD modelling of Sub-Scale Bread-Board igniter based on experimental assessment," in Proceedings of 51 AIAA/ASME/SAE/ASEE Joint Propulsion Conference, Orlando, Florida (U.S.A.), 2015. 
[2] B. F. Magnussen, B. H Hjertager, "On Mathematical Modeling of Turbulent Combustion with Special Emphasis on Soot Formation and Combustion," in Proceedings of $16^{\text {th }}$ Symp. (Int.) on Combustion (1976). Comb. Inst., Pittsburgh, Pennsylvania , USA, pp. 719-729, 1976.

[3] E. L. Petersen, D. F. Davidson, R. K. Hanson, "Kinetics Modeling of Shock Induced Ignition in Low Dilution $\mathrm{CH}_{4} / \mathrm{O}_{2}$ Mixtures at High Pressure and Intermediate Temperatures," Combustion and Flame, vol. 117, pp. 272-290, 1999.

[4] V. P. Zhukov, A. F. Kong, "Skeletal Kinetic Mechanism of Methane Oxidation for High Pressures and Temperatures," in Proceedings of $7^{\text {th }}$ European Conference for Aeronautics and Space Sciences (EUCASS), 2015.

[5] D. Goodwin, H. K. Moffat, R. L. Speth. (2017). Cantera: An Object-oriented Software Toolkit for Chemical Kinetics, Thermodynamics, and Transport Processes (Version 2.6). [Online]. Available: http://www.cantera.org 